\title{
LEAVING NO ONE BEHIND: A PROTEÇÃO INTERNACIONAL HUMANITÁRIA DOS DIREITOS DAS PESSOAS COM DEFICIÊNCIA EM ZONAS DE CONFLITO NA PERSPECTIVA DOS DEVERES
}

\section{LEAVING NO ONE BEHIND: PEOPLE WITH DISABILITY RIGHTS IN CONFLICT ZONES UNDER HUMANITARIAN INTERNATIONAL PROTECTION AND THE DUTIES PERSPECTIVE}

\author{
Daury César Fabriz ${ }^{1}$ \\ Julio Pinheiro Faro Homem de Siqueira ${ }^{2}$ \\ Schamyr Pancieri Vermelho ${ }^{3}$
}

\section{RESUMO}

O presente artigo tem por objetivo a análise e compreensão da proteção internacional humanitária dos direitos das pessoas com deficiência, em situação de conflito, na perspectiva dos deveres fundamentais. Investiga-se como os deveres podem contribuir para a proteção e concretização dos direitos das pessoas com deficiência submetidas, direta ou indiretamente, a uma situação de conflito. A importância de estudos desse tipo reside na existência, no universo normativo, de um rol significativo de direitos para esses indivíduos, sem a efetiva aplicação prática, o que gera, por consequência, a sensação de ausência de proteção normativa. No entanto, como se mostra, essa é uma conclusão falaciosa, uma vez que há um erro lógico na reivindicação de direitos, principalmente por meio de normas, ao Estado, já que, na verdade, a concretização dos direitos depende de algo muito simples: o cumprimento dos deveres por parte de todos os cidadãos. Para o desenvolvimento da pesquisa é utilizado o método dialético dialógico, na busca por uma perspectiva inovadora no enfrentamento das questões que envolvem a concretização dos direitos humanos.

Palavras-chave: Direito Internacional Público; Direito Humanitário; Deveres Humanos; Direito Humanos; Pessoas com Deficiência.

\footnotetext{
${ }^{1}$ Doutor e Mestre em Direito pela UFMG; Professor Associado III do Departamento de Direito da UFES; Professor Doutor Nível I da FDV (Graduação/Mestrado/Doutorado); Líder do no Grupo de Pesquisa "Estado, Democracia Constitucional e Direitos Fundamentais"; Sociólogo e Advogado. Faculdade de Direito de Vitória - FDV - Brasil. ORCID: http://lattes.cnpq.br/7280691457104972 Lattes: https://orcid.org/0000-0002-3781-5890 E-mail: daury@terra.com.br

${ }^{2}$ Mestre em Direitos e Garantias Fundamentais pela FDV; Pesquisador no Programa de Pós-Graduação em Direito da FDV no Grupo de Pesquisa "Estado, Democracia Constitucional e Direitos Fundamentais"; Professor de Teoria do Estado, Direito Constitucional e Direito Previdenciário; Membro do Centro Local de Inteligência e Prevenção de Demandas Repetitivas da Seção Judiciária do Rio de Janeiro; Servidor Público Federal. Faculdade de Direito de Vitória - FDV - Brasil. ORCID: https://orcid.org/0000-00025592-0416 Lattes: http://lattes.cnpq.br/1936096236504255 E-mail: pesquisa.jpfhs@ gmail.com

${ }^{3}$ Graduanda em Direito pela FDV; Pesquisadora no Programa de Pós-Graduação em Direito da FDV no Grupo de Pesquisa "Estado, Democracia Constitucional e Direitos Fundamentais". Faculdade de Direito de Vitória - FDV - Brasil. Lattes: http://lattes.cnpq.br/4519900851911184 E-mail: schamyrp@ gmail.com
} 


\begin{abstract}
The purpose of this article is to analyze and understand the international humanitarian protection of people with disabilities rights in conflict zones, from the perspective of fundamental duties. The study investigates how the perspective of duties can contribute to the protection and realization of the rights of people with disabilities submitted, directly or indirectly, to an armed conflict situation. This study is necessary because there are, in the normative universe, many rights for these people, without the practical application, which, consequently, cause the sensation of lack of normative protection. The present study shows that this is a fallacious conclusion, because there is a logical error in the claim of rights to the State, since, in fact, the realization of the rights depends, strictly, on the fulfillment of the duties on the part of all citizens. For the development of the research, it is employed the dialogical dialectical method, looking for an innovative perspective in facing the issues that involve the realization of human rights.
\end{abstract}

Keywords: International Public Law; Humanitarian Law; Human Duties; Human Rights; People with Disabilities.

\title{
1. INTRODUÇÃO ${ }^{4}$
}

O Comitê Internacional da Cruz Vermelha conceitua o direito internacional humanitário como "o conjunto de regras que procuram, por questões humanitárias, limitar os efeitos dos conflitos armados", de maneira a "proteger pessoas que não estão ou não mais estão participando das hostilidades e a restringir os meios e os métodos de guerra", por isso é que esse ramo do direito "é também conhecido como o direito da guerra ou o direito dos conflitos armados". Se a história desse ramo do direito internacional público, por um lado, é antiga e remonta às antigas civilizações, por outro, a idade de sua codificação se confunde com a da Cruz Vermelha, porque ambos surgiram com o propósito de prestar socorro aos militares feridos em conflitos armados, podendo-se firmar como o marco de seu surgimento o Convênio de Genebra de 1864, cujo texto foi por último modificado em 1977 (VALLADARES, 2006).

Com o tempo, as atividades da Cruz Vermelha se expandiram, a ponto de abranger a assistência humanitária em favor das vítimas diretas e indiretas dos conflitos armados, bem como contribuir para a proteção de seus direitos (VALLADARES, 2006). Portanto, quando

\footnotetext{
${ }^{4}$ As seções 1, 2 e 4 foram escritas pelo primeiro autor, com a revisão do segundo. As seções 3 e 5 foram escritas pelo segundo autor, com a revisão do primeiro. $\mathrm{O}$ terceiro autor orientou a escrita. A ordem em que os autores aparecem reflete o volume de suas contribuições para o trabalho. O trabalho foi produzido no seio do Grupo de Pesquisa "Estado, Democracia Constitucional e Direitos Fundamentais" do PPGD/FDV.
} 
se fala em direito internacional humanitário, o propósito é o de proteger os direitos das pessoas que, embora não façam parte dos conflitos armados, a eles estão sujeitas, como é o caso dos civis, em especial crianças, idosos e pessoas com deficiência, médicos, religiosos, entre outros.

O direito internacional humanitário não se confunde, porém, com o direito internacional dos direitos humanos. Apesar de ambos serem partes do direito internacional público que se ocupam da proteção dos seres humanos, ou seja, que interagem ente si, existem temas específicos a cada um. A diferença mais evidente é o âmbito de atuação, já que o direito humanitário foca tão somente nas situações de conflito armado, com o propósito de limitar ou diminuir os sofrimentos das pessoas sujeitas, por escolha alheia, à situação de conflito ou guerra armada. Logo, ao se falar em proteção internacional humanitária dos direitos, o que se abrange é a proteção dada a determinados direitos em situações de conflitos armados. O tema proposto no presente trabalho envolve a proteção aos direitos das pessoas com deficiência (PcD) em situação de conflito armado.

O entendimento sobre o que se denomina proteção internacional humanitária de direitos das PcD passa, necessariamente, por duas questões. A primeira delas consiste em entender o que é a deficiência, a partir, obviamente, do modelo adotado pelo direito internacional público. Essa questão é desenvolvida na próxima seção. A segunda, abordada na terceira seção, liga-se à proteção humanitária reconhecida em documentos internacionais sobre os direitos dessas pessoas. Por fim, como se pode tranquilamente observar na prática, o mero reconhecimento dos direitos não é suficiente para concretizá-los, de maneira que é necessário criar as oportunidades para que as PcD possam exercê-los plenamente, conforme suas próprias escolhas. É dizer, na quarta seção, propõe-se enxergar a questão da concretização dos direitos das $\mathrm{PcD}$, em situação de conflitos armados, a partir da abordagem dos deveres, a qual é, aqui, denominada abordagem do comprometimento social.

O trabalho aqui desenhado utiliza do método dialético, mediante a discussão dialogada, para desenvolver argumentos e compartilhar conhecimentos e opiniões, na busca por uma perspectiva inovadora no enfrentamento das questões que envolvem a concretização dos direitos humanos. Essa perspectiva é a dos deveres humanos, que pretende demonstrar como é possível dar mais eficácia aos direitos humanos reconhecidos em documentos internacionais, especialmente a grupos de pessoas cujas oportunidades de exercê-los é nula ou baixa. A grande vantagem desse método é permitir que o conjunto ideológico do pesquisador lhe sirva para assumir uma atitude objetiva (ou científica), posicionando-se 
criticamente perante o objeto pesquisado, permitindo, com isso, rever suas convicções e reformulá-las.

\section{O QUE É DEFICIÊNCIA}

A deficiência, em termos gerais, é a inaptidão de fazer algo. A origem etimológica do vocábulo, aliás, permite essa acepção, já que a palavra deficiente deriva do latim deficiens, deficientis, que quer dizer falho, incompleto, limitado. Mitra (2006) aponta que, embora o leigo tenha facilidade em dizer o que é deficiência, igual tranquilidade inexiste entre os especialistas, já que não há um consenso sobre o conceito. O mais próximo de uma concordância talvez esteja, segundo Couser (2005), em entender a deficiência como um elemento inevitável da experiência humana, como um aspecto fundamental da diversidade humana. Na verdade, essa é uma visão diferente da tradicional sobre a deficiência, podendo ser denominada, para diferenciação, como a visão contemporânea, na qual a deficiência deixa de ser vista como uma tragédia pessoal, que deve ser tratada como doença, e passa a ser vista como resultado da injustiça social, como ensinam Diniz (2010) e Bampi, Guilhem e Alves (2010). A perspectiva contemporânea, no entanto, é, ainda, minoritária, porque predomina a visão baseada na cultura da normalidade, que classifica seres humanos em categorias artificiais.

A perspectiva tradicional, ainda majoritária, é essencialmente individualista e coaduna com o modelo biomédico, pelo qual a deficiência é uma consequência da lesão corporal, devendo a pessoa ser submetida a cuidados biomédicos específicos. A base desse modelo é a Classificação Internacional das Deficiências, Incapacidades e Desvantagens (CIDID) da Organização Mundial da Saúde (OMS), publicado em 1976. De acordo com a OMS (1980), Farias e Buchalla (2005) e Diniz e Medeiros (2007), a deficiência (impairment) refere-se a perdas ou a anormalidades psicológicas, físicas ou anatômicas, relativas à estrutura do corpo ou à função de um sistema ou órgão, podendo ser permanente ou não; a incapacidade (disability) refere-se a limitações individuais ou a restrições no desempenho de uma atividade, provocadas por lesões; e a desvantagem (handicap) reflete em como o indivíduo, incapaz ou deficiente, se adapta ao seu entorno, quais barreiras ele enfrenta para cumprir um papel ou atingir um objetivo. Pelo modelo biomédico verifica-se que a lesão corporal (ou doença) leva à deficiência, que implicará numa incapacidade e gerará uma desvantagem ao indivíduo. Portanto, o problema é 
individual, não social, ou seja, para esse modelo, segregação social, desemprego, baixa escolaridade e outros tipos de opressão à pessoa com deficiência decorrem da inabilidade do corpo lesado em realizar um trabalho produtivo (cf. DINIZ, 2010; BARCELLOS e CAMPANTE, 2012), não da falta de comprometimento social para incluir, da melhor forma possível, essas pessoas.

Em 1972, antes mesmo da publicação do CIDID pela OMS, foi fundada no Reino Unido a Union of the Physically Impaired Against Segregation (UPIAS), a primeira organização política formada e administrada por deficientes para deficientes. A proposta da UPIAS era redefinir a deficiência em termos de exclusão social, como uma forma particular de opressão social, em lugar de como o resultado da lesão do corpo que leva à incapacidade, o que contribuiu para redefini-la em termos sociológicos, afastando-se do viés biomédico até então presente (DINIZ, 2010; BEZERRA, 2008). O resultado foi, consoante Diniz (2010, p. 20), uma "separação radical entre lesão e deficiência: a primeira seria o objeto das ações biomédicas no corpo, ao passo que a segunda seria entendida como uma questão da ordem dos direitos, da justiça social e das políticas de bem-estar". Entretanto, a OMS não acolheu, em 1976, ao elaborar a CIDID, essa nova perspectiva. Apesar disso, a distinção proposta pela UPIAS ganhou força na década de 1980, quando a deficiência se tornou "uma experiência de opressão compartilhada por pessoas com diferentes tipos de lesões", que enfrentavam vários tipos de barreiras sociais impeditivas de sua independência como seres humanos (DINIZ, 2010, pp. 34, 23 e 57). Surgia o que ficou conhecido como modelo social, pelo qual a deficiência não resultaria de lesões corporais, mas da existência de situações de opressão social, deslocando a deficiência “da alçada tão-somente biomédica, fundada em mensuração, evidências, tratamento e cura, para uma compreensão moral e cultural de que inúmeros obstáculos estão no exterior dos corpos, no ambiente material e moral que os circunda" (MARTEL, 2011, p. 91), isto é, transferiu-se "a responsabilidade pelas desvantagens das limitações corporais do indivíduo para a incapacidade da sociedade em prever e se ajustar à diversidade" (BAMPI, GUILHEM e ALVES, 2010).

A prevalência do modelo biomédico, decorrente da CIDID, adveio de uma necessidade classificatória observada pela OMS em relação à Classificação Internacional de Doenças (CID), que, à época, não refletia a complexidade das consequências de doenças, incluído o caso das deficiências. A CIDID surgiu, assim, de acordo com 
Hutchinson (1995), para melhorar a CID, estabelecendo um catálogo internacional oficial de deficiências, incapacidades e desvantagens baseado na CID. A CIDID revigorou o modelo biomédico, atualizando-o. Mas não é só por isso que os esforços da UPIAS pela mudança de concepção não surtiram os efeitos esperados. O motivo principal é que o modelo biomédico não foi exatamente recuperado. A análise da CIDID permite verificar que ela foi além do padrão até então seguido pela CID: "evitou-se utilizar a mesma palavra para designar as deficiências, incapacidades e desvantagens", de maneira que, enquanto "para uma deficiência foi adotado um adjetivo ou substantivo, para uma incapacidade, um verbo no infinitivo e para uma desvantagem, um dos papéis de sobrevivência no meio físico e social" (AMIRALIAN et ali., 2000). O resultado foi um afastamento do modelo biomédico de um viés quase matemático na abordagem das deficiências e incapacidades e sua aproximação de uma abordagem em que o indivíduo possa apresentar alguma deficiência, uma lesão corporal, que pode não ser incapacitante (ausência de prejuízo individual) ou não ser desvantajosa (ausência de prejuízo social para o indivíduo), o que permite apontar o surgimento de uma nova variante do modelo biomédico, porque ainda se percebia a deficiência como decorrência da lesão no corpo do indivíduo e de os prejuízos serem dele.

A CIDID, embora tenha distinguido deficiência, incapacidade e desvantagem, não foi suficiente para estabelecer um consenso. Durante duas décadas, entre 1980 e 2001, houve acirrados debates sobre a adequação dos conceitos de lesão, incapacidade, deficiência e desvantagem (DINIZ, 2010). A CIDID, revisada durante a década de 1990, foi substituída, em 2001, pela Classificação Internacional de Funcionalidade, Deficiência e Saúde (CIF), a qual mudou a perspectiva sobre a deficiência como consequência de doenças ou lesões, para a deficiência como consequência de questões de saúde (DINIZ, 2010). O modelo social, que até então não havia sido adotado, foi absorvido para compor um novo, o modelo biopsicossocial, também conhecido como modelo biossocial. Adotouse a visão sociológica da deficiência sem abandonar a biomédica. O resultado foi a revisão do sistema classificatório da OMS, com o abandono de uma classificação de corpos com lesões, como fazia a CIDID, para uma avaliação complexa da relação entre as desvantagens experimentas por uma pessoa e as oportunidades que a sociedade lhe franqueia (cf. DINIZ, 2010; DINIZ e MEDEIROS, 2007). Portanto, com o modelo biossocial, abandonou-se o conceito individualista de deficiência (questão estritamente 
pessoal), para se adotar um conceito mais amplo indicativo de restrições de participação social. Deixou-se de enquadrar a deficiência como questão de anormalidade e passou-se a vislumbrá-la como falta de oportunidades sociais (falta de participação ou inserção social), promovidas por uma lesão corporal (corpo deficiente) e/ou barreiras sociais (sociedade deficiente).

O modelo biopsicossocial, atualmente adotado pela OMS, com a CIF, é tridimensional, e, mesmo que as dimensões psicológica e social tenham sido abrangidas, o que prevalece, ainda, é o viés biomédico. A perspectiva tridimensional incorpora as críticas ao modelo social, cujo argumento inicial era de que a eliminação de barreiras postas pela sociedade permitiria às $\mathrm{PcD}$ demonstrar a sua potencialidade produtiva, dando a impressão de que bastaria remover tais barreiras, argumento que, todavia, demonstra a falta de conhecimento sobre as diversas experiências sobre a deficiência, desconsiderando os deficientes que, eliminadas as barreiras, ainda assim não alcançarão sua independência nem terão capacidade para trabalhar (DINIZ, 2010). O modelo biossocial não parte de soluções únicas para a questão da deficiência. Ao contrário, sua base é o dever de cooperação mútua, o comprometimento social que revela a interdependência entre as pessoas. Portanto, para esse modelo, cuja adoção é crescente, mas que ainda depende de ajustes em sua execução, a deficiência é um estilo de vida que reivindica o "direito de estar no mundo" (DINIZ, 2010, p. 70), o direito de ser reconhecido e tratado como uma pessoa igual a todas as outras, sem estigmas.

A Convenção sobre os Direitos das Pessoas com Deficiência (CDPD), que é ao mesmo tempo um documento de proteção internacional de direitos humanos e humanitária, adota o modelo biossocial, como se pode extrair de seu preâmbulo e do artigo 1, nos quais se reconhece que a deficiência é um conceito em evolução e que resulta da interação entre pessoas deficientes e barreiras que impedem a plena e efetiva participação dessas pessoas na sociedade em igualdade de oportunidades com as outras pessoas. Com essa concepção, a CDPD tornou a deficiência "parte da experiência humana" (DHANDA, 2008, p. 45), isto é, uma das formas de estar no mundo (DINIZ, BARBOSA e SANTOS, 2009), um estilo de vida. É de se notar, nesse sentido, como se extrai do artigo 11, que os Estados signatários devem tomar "todas as medidas necessárias para assegurar a proteção e a segurança das PcD que se encontrarem em situações de risco, inclusive situações de conflito armado, emergências humanitárias e ocorrência de 
desastres naturais". Em outras palavras, a CDPD reconhece que é necessário haver um comprometimento social (no caso dos Estados, a realização de políticas públicas efetivas) voltado para a proteção, inclusão e participação cidadã das $\mathrm{PcD}$, de maneira a lhes conferir oportunidades equitativas para desfrutar de sua autonomia, mesmo que não alcancem sua plena independência.

O conceito técnico de deficiência envolve, portanto, duas deficiências: a do corpo, o que o aproxima do modelo biomédico, e a da estrutura social, o que o aproxima do modelo social. A proteção a ser conferida aos direitos das PcD é, por isso, dupla: por um lado, ao Estado cumpre prover a essas pessoas suas necessidades básicas, o que é normalmente feito mediante políticas assistenciais, de fundo financeiro; por outro, o Estado e também a sociedade, coletiva ou individualmente considerada, têm o dever de criar oportunidades que viabilizem às $\mathrm{PcD}$ o exercício de seu conjunto capacitário (para utilizar uma expressão próxima à utilizada por Sen) ou conjunto de capacidades (que é expressão próxima, mas não exata à utilizada pelo economista indiano). Isso quer dizer que as pessoas deficientes devem deixar de ser tratadas como objeto de políticas assistencialistas e de tratamentos biomédicos, para serem vistas como sujeitos de direitos, como anota Flávia Piovesan (2012). Fala-se, então, em Estado e sociedade efetivos para formar cidadãos ativos.

\section{A PROTEÇÃO HUMANITÁRIA DAS PESSOAS COM DEFICIÊNCIA}

A discussão a respeito do dever de criar oportunidades que viabilizem às $\mathrm{PcD}$, especialmente daquelas em situações de conflito, a busca pelo seu bem-estar é profícua. Todavia, antes de trazer essa discussão, é necessário introduzir outra. É que em um mundo moderno, obcecado por estatísticas, há uma enorme tendência em reduzir a importância de certos acontecimentos a números: "tendemos a medir o mal, a crueldade, a repugnância e a infâmia da vitimização pelo número de vítimas", de modo que os piores conflitos e tragédias passam a ser descritos como aqueles que deixaram o maior número de vítimas, fazendo que desapareça o valor de cada vida que permitiu a sua formulação (BAUMAN, 2004, p. 101). O reconhecimento dos direitos das PcD, em situação de conflito ou não, parece padecer do mesmo mal, de modo que a ideia transmitida pelos documentos internacionais, supranacionais e nacionais é de que quanto mais direitos reconhecidos no 
papel, maior o número de pessoas protegidas; parece que o bem-estar de cada indivíduo é, de alguma forma, substituído, não por um número, mas pela proteção que os direitos positivados, por si sós, parecem lhes reconhecer. Se, efetivamente, as normas definidoras de direitos tivessem aplicação imediata, o Judiciário, o Executivo e as funções essenciais ao Estado de Direito, por um lado, seriam meros apêndices do Legislativo, e, por outro lado, o recurso às políticas públicas e à intervenção judicial (judicialização) confirmariam que a aplicabilidade imediata é a exceção, não a regra. O teste empírico é, aqui, diário e, por isso, é prescindível a empiria científica para concluir que não basta reconhecer, é necessário colocar os direitos em prática (SARAMAGO, 1998), senão o que se têm são privilégios, exercidos por aqueles que têm acesso a oportunidades de colocar em prática direitos que estavam no papel.

O esforço das pessoas de direito internacional público por reconhecer determinados direitos, com a sua positivação em textos normativos, embora seja aclamável, nada mais significa, portanto, que tinta no papel. A singela leitura dos documentos internacionais permite concluir que os direitos positivados são genéricos e sua normatização não observa a individualidade. As políticas públicas que se baseiam nesses textos raramente trabalham com a individualização, o máximo que elas fazem, em sua grande maioria, é especificar um grupo, que pretendem homogêneo. A Convenção da ONU sobre Direitos das Pessoas com Deficiência (CDPD), em seu artigo 11, revela, com muita clareza, a inexistência dessa individualização. E, ainda que se alegue que os tratados e convenções internacionais sobre direitos humanos sejam mais abrangentes/genéricos e que devem ser especificados pelas demais pessoas de direito internacional público, a observação da prática permite concluir que as especificações não ocorrem, nem mesmo no bojo de cada política pública.

A ajuda humanitária destinada a proteger e a socorrer os indivíduos inseridos, por força alheia à sua vontade, em situações de conflitos armados, com o propósito de evitar ou de amenizar sofrimentos maiores, tem permitido duas conclusões praticamente consensuais: de um lado, ela tem sido eficaz em muitas situações, notadamente na assistência dada, em geral, à população submetida a conflitos armados e a desastres naturais; de outro lado, ela tem sido débil em relação a grupos particularmente vulneráveis a essas crises, como no caso das PcD submetidas a esse tipo de situações. Essa percepção foi registrada pela Humanity \& Inclusion, (antes, Handicap International, 2015), uma 
organização sem fins lucrativos, em um relatório publicado em 2015, baseado nos resultados de uma consulta global a $484 \mathrm{PcD}, 118$ organizações para $\mathrm{PcD}$ e organizações humanitárias, no qual se concluiu, entre outras coisas, que $75 \%$ das PcD não têm acesso adequado a serviços básicos como acesso à saúde, cuidados psicossociais, assistência alimentar e serviços de água, saneamento e higiene, e que, ainda que alguns desses serviços ou outros considerados essenciais estejam disponíveis, $32 \%$ das pessoas não têm informação sobre a sua existência, ou seja, não têm acesso a oportunidades para garantir um mínimo de bem-estar próprio. Além disso, o relatório revelou que $61 \%$ das $\operatorname{PcD}$ são assistidas por pessoas de sua própria família, o que é crítico para a sua qualidade de vida.

As provas empíricas de que a positivação de um direito não significa a sua proteção são, nesse sentido, muito claras. Além disso, elas revelam que as crises humanitárias, como as situações de conflito armado, aumentam a vulnerabilidade de grupos como PcD e idosos. Considerada a estimativa feita pela OMS em 2018, segundo a qual cerca de $15 \%$ da população mundial tem algum tipo de deficiência, o que significa mais de um bilhão de pessoas, e que o número tende a crescer na ocorrência de desastres naturais ou de conflitos armados, a falta de proteção é alarmante. Assim, como aponta Alt (2017), “apesar do amplo conhecimento de que pessoas com deficiência estão mais expostas a riscos em crises humanitárias, na prática sua vulnerabilidade acaba sendo exacerbada", e esse aumento tem como causas, dentre outras, a falta de mecanismos para a identificação de quem são as $\mathrm{PcD}$, a ausência de especialistas em organizações humanitárias e o não envolvimento de indivíduos com deficiência no ciclo das políticas de intervenção humanitária. O resultado da intensificação foi a constatação de que seria necessária uma mobilização internacional, no sentido de que os ativistas e as organizações humanitários deveriam assumir um compromisso com a criação de oportunidades adequadas para que as $\mathrm{PcD}$ pudessem alcançar o seu bem-estar.

A mobilização em torno de um compromisso social internacional resultou não só na CDPD, que embora aborde o grupo das PcD de maneira mais ampla, trouxe um conceito mais atualizado, com base em um modelo mais bem desenvolvido, de deficiência. Também conhecida como Convenção de Nova Iorque, a CDPD foi elaborada em 2006 e, desde então, há uma tendência a se utilizar o seu modelo e conceito para uma melhor identificação das $\mathrm{PcD}$. Na mesma linha, embora não estejam propriamente voltados para esse grupo vulnerável, foram elaborados o Marco de Sendai para a Redução 
do Risco de Desastres 2015-2030, os ODS (anteriormente, objetivos de desenvolvimento do milênio) e a Norma Humanitária Essencial para a Qualidade e Prestação de Contas, todos focados na melhoria qualitativa da assistência humanitária. E, seguindo essa tendência, durante a Conferência Mundial de Ajuda Humanitária, em 2016, foi apresentada a Carta sobre a Inclusão de Pessoas com Deficiência nas Ações Humanitárias (CIPDAH), que ajudou a incentivar a realização de ações concretas, como a formação de grupos de trabalhos, o financiamento por grandes doadores de projetos de inclusão social de grupos vulneráveis submetidos a crises humanitárias, a coleta de dados sobre PcD envolvidas em conflitos armados ou desastres naturais e a realização de fóruns internacionais (ALT, 2018).

De acordo com os especialistas, há três causas centrais para melhor tratar a questão dos direitos das $\mathrm{PcD}$ em situação de crise humanitária: a coleta correta de informações, a presença de PcD no processo decisório, não apenas das organizações humanitárias, mas de todas as pessoas internacionais envolvidas, e a atuação de especialistas em inclusão, a fim de que haja não apenas apoio técnico, como também a garantia da qualidade dos projetos e das atividades realizados (ALT, 2018). Para se ter uma ideia sobre como essas três causas podem servir para melhorar ou piorar a qualidade da proteção às $\mathrm{PcD}$, em 2016 o Alto Comissariado das Nações Unidas para os Refugiados (ACNUR) realizou com a ONG Humanity \& Inclusion uma pesquisa, num campo de refugiados sírios na Jordânia, para identificar, entre eles, quem estaria em condição de pessoa com deficiência. Nesse levantamento foram utilizados dois tipos de questionários, o tradicional, que identificou 2,36\% de PcD, e o questionário do Grupo de Washington (WGQ), pelo qual 27,55\% das pessoas, no mesmo grupo, tinham deficiência. A diferença nos resultados deve-se a como as informações são obtidas, ou seja, como as perguntas são colocadas para todas as pessoas, inclusive as PcD. A leitura dos documentos da Humanity \& Inclusion e do website do WGQ permite concluir que o questionário não faz referências diretas ao termo deficiência ou aos seus correlatos que criem alguma situação de estigma, mas emprega uma linguagem neutra, que permite, a partir das necessidades relatadas e das dificuldades apontadas pelas pessoas, identificar quem é $\mathrm{PcD}$ e quem não é.

Logo se vê que a questão da proteção das $\mathrm{PcD}$ e da concretização de seus direitos não é das mais simples. É necessário tomar medidas efetivas para garantir o comprometimento social voltado para a criação de oportunidades adequadas para que as 
PcD possam exercer os seus direitos, da maneira como lhes for melhor, e não da maneira como os outros achem como mais adequada. Portanto, quando as PcD tiverem as oportunidades adequadas, que as coloquem em uma situação equitativa com todas as demais (excluindo, assim, a sua situação de vulnerabilidade), para exercerem o seu livrearbítrio, nesse momento será possível afirmar que estão devidamente protegidas e, assim, que a regra primeira de toda a humanidade terá sido efetivamente praticada: todos os seres humanos são iguais em direitos. A regra é repetida, das formas mais variadas, nos mais diferentes documentos (nacionais, supranacionais ou internacionais), mas tem um único propósito: estabelecer a necessidade de que sejam envidados esforços (sejam cumpridos obrigações e deveres) para que ela se torne efetiva socialmente.

\section{OS DEVERES COMO CONDIÇÃO PARA A PROTEÇÃO HUMANITÁRIA EFICAZ}

A regra todos os seres humanos são iguais em direitos é, usual e equivocadamente, repetida com um complemento, que, também usual, porém acertadamente, a torna, em geral, sem sentido: todos os seres humanos são iguais em direitos e deveres. É dizer, os seres humanos são, de fato, iguais em direitos, mas não em deveres, porque esta igualdade só existe em duas situações. A primeira situação é aquela na qual não há diferença de natureza alguma, já que todos são literalmente iguais; no entanto, isso não é factível, mas fictício (cf. e.g. RAWLS, 1999), e, portanto, irrealizável, a não ser teoricamente. A segunda situação é factível, mas é uma consequência de uma prévia falta de equidade, ou seja, haverá, entre todos os seres humanos, igualdade de direitos e de deveres, tão somente se forem oportunizadas as adequadas oportunidades para que as pessoas em situação vulnerável superem essa sua condição. Obviamente, é preferível, em temos de mudança, a segunda situação, mas a pergunta de valor inestimável que a circunda é: de que maneira isso pode serfeito?

A resposta é ao menos tão antiga quanto a necessidade, verificada, de se concretizar os direitos humanos reconhecidos e declarados ao longo do tempo. Há, nesse sentido, alguns documentos internacionais voltados para a busca de igualdade de oportunidades para as PcD. A Resolução da ONU 37/52, de 1982, estabelece o Programa de Ação Mundial para as Pessoas Deficientes, baseando-se na constatação empírica de 
que, na grande maioria das vezes, "é o meio que determina o efeito de uma deficiência ou de uma incapacidade sobre a vida cotidiana da pessoa", a qual se vê "relegada à invalidez quando lhe são negadas as oportunidades de que dispõe, em geral, a comunidade, e que são necessárias aos aspectos fundamentais da vida" (item 21). Nesse sentido, identificar as PcD é o primeiro passo para buscar a igualdade de oportunidades, porque a partir dela é possível identificar e eliminar os obstáculos à sua participação plena, de maneira que, por exemplo, "quando for pedagogicamente factível, o ensino deve ser realizado dentro do sistema escolar normal, o trabalho deve ser proporcionado em emprego aberto, facilitando-se a habitação da mesma forma que para a população em geral” (item 22). Note-se que já em 1982, a ONU destacava que a existência de oportunidades adequadas é uma via de mão dupla: "assim como as pessoas deficientes têm direitos iguais, têm também obrigações iguais", ou seja, as PcD têm o dever de participar da construção da sociedade, de modo que, por isso mesmo é "que se deve oferecer aos jovens deficientes oportunidades de carreira e formação profissional, e não pensões de aposentadoria prematura ou de assistência pública" (item 26). Portanto, as PcD têm não apenas direito a oportunidades adequadas ao exercício de suas liberdades, mas também o dever de se comprometer com a sociedade, já que elas não se reduzem às limitações manifestadas, devendo-se focalizar as suas capacidades (item 27). A Resolução da ONU 48/96, de 1993, seguindo a mesma lógica, aprova Normas sobre Equiparação de Oportunidades para $\mathrm{PcD}$ e incita os Estados-membros a adotar as regras no desenvolvimento de programas nacionais em matéria de deficiência, sempre com foco em suas capacidades, não em suas limitações.

As duas resoluções referidas se relacionam fortemente com a CDPD, em que pese o propósito desta se direcionar aos direitos e liberdades das $\mathrm{PcD}$, e não a seus deveres. No entanto, não se pode imputar à Convenção de Nova Iorque uma incompletude, até mesmo porque, a partir do momento em que as $\mathrm{PcD}$ tiverem acesso a oportunidades adequadas, que afastem a sua condição de vulnerabilidade no exercício de direitos, em comparação com a comunidade em geral, elas passarão a integrar essa comunidade e, então, terão os mesmos deveres. É por isso que todos os documentos internacionais e nacionais, sem exceção, focalizam nos direitos das $\mathrm{PcD}$, não apenas para conhecimento e para permitir a reivindicação, mas também para indicar aos Estados quais as medidas necessárias para assegurar a proteção e a segurança das $\mathrm{PcD}$ em situação de risco, como 
conflitos armados, emergências humanitárias e desastres naturais (o que justifica a redação do artigo 11 da CDPD). É de se notar, porém, que nenhum desses documentos citados direciona-se especificamente à proteção humanitária. Esses documentos são importantes embora sejam complementares em relação às quatro Convenções de Genebra de 1949 e seus Protocolos Adicionais de 1977, que compõem o núcleo do direito internacional humanitário, tendo como propósito proteger pessoas que não participam das hostilidades (civis, profissionais da saúde, prestadores de ajuda humanitária, soldados feridos e/ou enfermos, prisioneiros etc.) e substituindo as convenções anteriores sobre direito de guerra. A leitura das quatro Convenções permite afirmar que nenhuma delas se direciona, especificamente, para os direitos das $\mathrm{PcD}$, muito embora disponham sobre a proteção e a segurança de todos os indivíduos submetidos, direta ou indiretamente, a conflitos armados.

Portanto, pode-se afirmar que a proteção e a segurança das PcD submetidas a conflitos armados são feitas, juridicamente, por um conjunto, não codificado nem consolidado, de documentos voltados para a atuação dos Estados no oferecimento de oportunidades que sejam adequadas ao exercício de direitos reconhecidos à comunidade em geral. Logo, é possível dizer que a proteção humanitária consiste nos esforços para proteger o bem-estar de indivíduos em perigo, como nos conflitos armados, mediante ações que garantam, de direito e de fato, o padrão mínimo de dignidade (FORSYTHE, 2001). É o caso das PcD, cujos direitos estão suficientemente reconhecidos em documentos nacionais e internacionais, mas que, no entanto, não têm força suficiente para, por si sós, concretizarem direitos. Nesse sentido, organizações internacionais, como a Cruz Vermelha, assumem o papel de realizar diálogos diplomáticos com Estados e Estados em potencial (insurgentes, beligerantes movimentos de liberação nacional), com o intuito de garantir a realização de políticas públicas que beneficiem pessoas afetadas, direta ou indiretamente, por conflitos armados. Obviamente, nem sempre será possível contar com a realização dessas políticas ou esperar que elas sejam implantadas imediatamente. Por mais que se possa argumentar que os direitos são imediatamente aplicáveis, oportunidades não advêm de mero reconhecimento jurídico, são necessárias atitudes para que o bem-estar mínimo seja desfrutado pelos indivíduos, o que somente é possível se houver comprometimento social. É aqui que entra a perspectiva dos deveres humanos como condição para a proteção humanitária eficaz. 
O comprometimento social é a primeira fase da teoria do ciclo do bem-estar humano, e consiste não apenas em mudanças jurídicas, mas, também e principalmente, em uma mudança cultural da própria sociedade, que deve passar a compreender que os direitos só se concretizam quando aos indivíduos são dadas as oportunidades adequadas para optar por seu exercício. Todavia, como as oportunidades normalmente não existem em estado natural na sociedade, dependendo de comportamentos humanos que as criem, aquelas pessoas que já têm uma maior capacidade de contribuir com a sociedade, devem assumir o compromisso de realizar a equidade, em razão do objetivo fundamental da humanidade, a fraternidade. Isso porque a fraternidade permite a equidade e somente em um mundo sem desigualdades haverá liberdade, do contrário, teremos apenas privilégios, os quais permanecerão, como tais, sendo desfrutados apenas por quem tem capacidade de criar as próprias oportunidades. Portanto, a mudança cultural propugna nada mais que a mudança da sociedade baseada no individualismo para uma sociedade baseada na cooperação e no apoio recíprocos entre os seres humanos.

A mudança paradigmática proposta não é fácil de se implantar, especialmente quando se verifica que, na prática, os direitos humanos, apesar de sua universalidade, onipresença e penetração, só podem ser acionados por pequenas elites, bem informadas, assistidas por assessores jurídicos, com poder econômico suficiente para arcar com um caminho judicial especializado e menos conhecido (HESPANHA e BELEZA, 2011). Essa percepção, mais realista que pessimista, funda-se em exemplos empíricos, que advêm, por exemplo, dos objetivos de desenvolvimento sustentável (ODS) da Organização das Nações Unidas (ONU). Os relatórios do Programa das Nações Unidas para o Desenvolvimento (PNUD) demonstram que os ODS somente existem porque há países e regiões nos quais os direitos humanos não existem na prática, apenas no papel. Para se ter uma ideia do nível da disparidade no que tange à aplicação prática dos direitos humanos, basta pensar em tragédias naturais ocorridas em algum país desenvolvido (Estados Unidos da América, por exemplo, quando da passagem do furacão Katrina, em 2005) em contraste com algum país subdesenvolvido (como, por exemplo, Moçambique, após o ciclone Idai, em 2019, ou a Costa Rica, depois do furacão Matthew, em 2016) e, assim, analisar o tipo da ajuda humanitária, o volume de recursos doados e a recuperação da sociedade. Embora nas três situações haja seres humanos envolvidos, o que se percebe é que a importância deles é classificada segundo interesses econômicos dos Estados 
"beneficentes", o que influencia sobremaneira a ajuda humanitária, embora não se possa atribuir a organizações de assistência humanitária a pecha de interesseiros. O que o PNUD tenta superar, a partir dos ODS, é exatamente esse viés de privilégio que os direitos humanos assumem na prática, isto é: embora sejam universais, como se encontra nas várias declarações e tratados, o fato é que na prática muitos deles só são usufruídos por quem tem oportunidades de alcançá-los, ao passo que os grupos mais vulneráveis dependem de políticas públicas estatais ou de ajuda humanitária, mormente em casos em que o Estado é ausente. No entanto, os pesquisadores, especialmente aqueles que vivem em países africanos, asiáticos ou latino-americanos, já perceberam que os ODS são muito mais efetivos no papel que na prática (cf. SIQUEIRA e MTEWA, mimeo).

A proposta da teoria do ciclo do bem-estar humano é mudar, ao lado dos esforços que já têm sido feitos, como, por exemplo, a proposta dos ODS do PNUD, essa realidade. É claro que se tem a exata noção de que uma teoria, assim como uma única andorinha, não tem aptidão para trazer mudanças. Todavia, sabe-se que a forma de olhar para a realidade, a perspectiva adotada para solucionar problemas sociais e proteger direitos humanos, contribui, sobremaneira, para mudanças efetivas. A importância da primeira fase desse ciclo, isto é, a etapa do comprometimento social, é substancial, pois é ela a responsável por lançar as bases da mudança paradigmática que vem sendo proposta. Como a conduta de se comprometer exige como complemento substantivo, o comprometimento é com a geração de oportunidades, as quais, quando exercidas, resultam em bem-estar. Com isso em mente, a análise volta-se para a primeira etapa do ciclo.

O fundamento do comprometimento social não deriva, exclusivamente, da fraternidade nem da solidariedade. Isso porque as raízes etimológicas das palavras fraternidade (latina, fraternitas, fraternitatis, e grega, phratría) e solidariedade (latina, solidarium, solidum) remetem a uma mesma ideia, a responsabilidade recíproca baseada no interesse comum entre dois ou mais indivíduos, que tenham algum tipo de ligação relacional, pertencendo, por exemplo, a uma família, tribo ou irmandade, ou possuindo um débito comum (cf. CANDIDO, 2001; DUSSEL, 2006; BAYERTZ, 1999). Logo, nenhuma das duas ideias, por si sós, explicam, suficientemente, a primeira etapa do ciclo do bem-estar humano. Isso não quer dizer que, atualmente, não possa haver um novo entendimento sobre a fraternidade ou a solidariedade que as coloquem como possíveis 
fundamentos; todavia, a carga de ambiguidade seria grande e prejudicaria a adequação do embasamento. É necessário, então, procurar ideias que expressem melhor o compromisso social, porque a etapa não abrange tão somente a responsabilidade das pessoas dentro de determinados grupos em decorrência de uma relação baseada em interesses comuns, sua abrangência é muito maior, envolvendo, inclusive, pessoas para além de seu convívio e conhecimento, como é comum acontecer na ajuda humanitária.

O anonimato, que usualmente acompanha o compromisso social, é uma pedra angular importante na busca do fundamento teórico. No entanto, isso não quer dizer que ele derive da caridade, mas que decorre de um movimento de fuga do agir individualista em direção do agir altruísta, isto é, de um agir autocentrado/egocêntrico para um agir altercentrado. Certamente que esse é um modelo ideal e, assim, impraticável, porque o ser humano, em regra, direciona o seu comportamento ao seu próprio bem-estar. A opção que se afigura mais palpável e que parece ser a mais adequada para fundamentar a etapa do compromisso social é, nesse sentido, a abordagem que procura entender como cada indivíduo pode contribuir para a melhoria geral do bem-estar humano. Adota-se, então, o argumento de que cada pessoa atua para alcançar algo que seja de seu interesse e contribua para o seu próprio bem-estar, o que pode gerar um comportamento voltado apenas para si (ego) e também voltado, direta ou indiretamente, para o outro (alter), permitindo a cooperação orientada ao atendimento dos interesses da coletividade, assumindo-se uma condição de responsável por si e pelo próximo (cf. SEN, 2007 e 2008; SIQUEIRA, 2013). Diante disso, pode-se afirmar que, o altruísmo, tal qual a fraternidade e a solidariedade, também não é um ponto de partida adequado, porque há muita ambiguidade quanto ao uso do vocábulo, que pode ser utilizado para se referir a muitas coisas, como bons samaritanos, prática de caridade etc. (cf. KERR, GODFREY-SMITH e FELDMAN, 2004; MacFARQUHAR, 2018; KHALIL, 2004; TRIVERS, 1971). Mesmo assim, essas três ideias (solidariedade, fraternidade e altruísmo) convergem, em sua essência, para uma quarta ideia.

A cooperação é essa quarta ideia. Trata-se, caso assim se prefira pensar, de um gênero, cujas espécies abarcadas vão desde o individualismo utilitarista - as condutas da pessoa são autocentradas, voltadas para a melhoria do seu próprio bem-estar e, em extensão, mas nem sempre, ao da coletividade - até o altruísmo do bom samaritano - as condutas do indivíduo são altercentradas, de modo que abre mão da melhoria de seu 
próprio bem-estar em função da obtenção de bem-estar para outrem -, passando pela fraternidade e pela solidariedade. A cooperação pode ser entendida quando um indivíduo gera oportunidades que possam beneficiar outras pessoas, individual ou coletivamente consideradas, o que inclui amigos, parentes e, também, estranhos (cf. HENRICH e HENRICH, 2006). Para se ter uma clara ideia do significado disso, a ODS 17 do PNUD se baseia no entendimento de que todas as outras 16 ODS só poderão ser alcançadas se houver cooperação em nível global. A grande questão, porém, que pende sobre a cooperação humana, tem a ver com o modo como ela é praticada. Isso porque há, basicamente, duas maneiras distintas de cooperar.

A primeira forma de colocar a cooperação em prática ocorre a partir de normas sociais (jurídicas, religiosas etc.). Nesse caso, o ato de cooperar se torna compulsório e, se não executado, pode ser sancionado. Isso não é, efetivamente, cooperação, mas cumprimento de uma obrigação que, não fosse a imposição normativa, inexistiria. É por isso que não é adequada, como fundamento teórico da primeira fase da teoria o ciclo do bem-estar humano, a responsabilidade. Isso se deve ao fato de que toda responsabilidade decorre de uma obrigação que pode dizer respeito a atos, próprios e alheios, ou a coisas, ou seja, a responsabilidade se baseia em suportar um ônus ou em obter um bônus, dependendo da conduta. Ser responsável, considerando a cooperação como um gênero e afastando-se a questão da imposição, manifesta-se, com uma maior ênfase, em duas espécies, entre aquelas aqui nominadas: os individualistas utilitaristas e os altruístas bom samaritanos - exatamente os extremos. Em todas as outras espécies de cooperação, a responsabilidade só passa a existir se compulsória, de modo que o indivíduo não vai propriamente cooperar, mas evitar sofrer uma punição, um ônus.

A segunda forma é esperar que a cooperação seja posta em prática, ou seja, que ela seja executada de maneira natural. Nesse caso, o ato de cooperar é livre, não é uma obrigação nem gera uma responsabilidade, ele é empático. A cooperação efetiva é caracterizada pela empatia, etimologicamente derivada do grego empatheria, que significa a habilidade de entender os sentimentos de outra pessoa, de senti-los como se fossem nossos, ou, segundo uma conceituação mais usual, a empatia é a capacidade de se colocar no lugar do outro, compreendendo a sua experiência, sentindo-a e dela participando, sem, contudo, se tornar parte dela (cf. IOANNIDOU e KONSTANLIKAKI, 2008; TITCHENET 2014 e 1928; STUEBER, 2018; CUFF et al., 2016). De acordo com 
os especialistas, a partir de pesquisas realizadas tanto em seres humanos quanto em outros animais, sobre as origens do comportamento altruísta e empático, "a empatia é uma reação automática, sobre a qual temos controle limitado", de maneira que, salvo pequena parcela da humanidade, os psicopatas, "ninguém consegue se manter emocionalmente imune à situação dos outros", especialmente quando já se viveu aquele tipo de emoção (WAAL, 2010, pp. 69 e 108). Note que a empatia não é o fundamento principal dessa fase que ora se apresenta e desenvolve, mas o processo que permite o comprometimento de uma maneira mais sólida, como, aliás, observa Frans de Waal (2010, p. 130): “a empatia é o processo pelo qual nos damos conta da situação de outra pessoa. A solidariedade, em contraste, reflete a nossa preocupação com o outro e um desejo de fazer com que a sua situação melhore", de modo que o sentimento de empatia é, em geral, maior que os impulsos de solidariedade de uma pessoa. Frequentemente, entre os seres humanos, o agir solidário é um agir racional, salvo quando a identificação emocional é tão elevada que é capaz de afastar qualquer tipo de cálculo baseado em interesses e/ou preferências que compensem o esforço. Isso, todavia, não é cooperação, a qual exige um esforço, mas, provavelmente, decorre de um comportamento empático.

A empatia, embora seja um tema interessante para as relações humanas, não é o foco do trabalho aqui desenvolvido. A cooperação, sim. As muitas possibilidades resultantes da cooperação social humana é que embasam adequadamente a fase do comprometimento social. Inicialmente, é necessário esclarecer que, para a finalidade do presente trabalho, a cooperação é conceituada como o conjunto de comportamentos que beneficiam outros indivíduos (receptor) ou que beneficiam tanto o autor quanto o receptor (cf. MELIS e SEMMANN, 2010; RAND e NOWAK, 2013). De acordo com Melis e Semmann, o comportamento cooperativo, mesmo quando o receptor é de espécie distinta do autor, não é peculiaridade humana. Todavia, segundo Boyd e Richerson (2009, p. $3281 ; 1996$, p. 80), a maioria dos mamíferos sociais cooperam principalmente com seus parentes, enquanto a cooperação em larga escala é uma característica sui generis dos humanos, inclusive em termos evolutivos, até mesmo por uma questão de adaptabilidade.

No ponto em que a biologia se aproxima das ciências sociais, a teoria que talvez melhor explique a cooperação humana é a teoria da dupla herança, pela qual o fato de os seres humanos serem seres culturais é decorrência de seu passado evolutivo, que "favoreceu o surgimento de indivíduos capazes de agir de acordo com elementos 
culturais", o que, à sua vez, exerceu forte pressão seletiva sobre a genética de seus ancestrais (ALMEIDA, 2013, p. 246). Noutros termos, conforme Richerson e Boyd (2005 e 2013), a herança cultural, não apenas a genética, é crucial para entender o comportamento humano, do que se pode assumir que, ao contrário de outras espécies animais, a evolução humana abrange a rara evolução comportamental, ou seja, a cultura e a genética são heranças que se entrelaçam na história evolutiva humana. E é essa herança comportamental que explica a capacidade humana de se comprometer com o outro, tanto no nível da responsabilidade quanto no nível da empatia, isto é, trata-se de uma questão cultural.

Portanto, em síntese, pode-se afirmar que a cooperação é, também, uma herança cultural e sustenta a primeira fase da teoria do ciclo do bem-estar, o comprometimento social. A partir disso, é possível estabelecer, então, que, em determinada perspectiva, o jogo da cooperação é sempre ganha-ganha, em que, de um lado, o autor ganha em bemestar, e, de outro, o receptor ganha em oportunidade. Diante disso, a grande questão é que recursos e estratégias devem ser utilizados para manter a cooperação e controlar o efeito carona.

Como reiteradamente sublinhado, o comportamento humano varia entre dois extremos bem claros, o utilitarismo individualista e o bom-samaritanismo. O fato é que, na média, os seres humanos tendem à empatia e, assim, às diversas formas de cooperação, as quais podem se basear ou não na necessidade de recompensas, diretas ou indiretas. Assim, as estratégias e recursos que parecem ser os mais adequados são aqueles pelos quais há um retorno em bem-estar, que pode ser imediato - como a concessão de benefícios físcais - ou mediato - como a prestação de serviços públicos de melhor qualidade. Com isso, o modus operandi deve ser estabelecido pelas pessoas jurídicas de direito público, como os Estados e as Organizações Internacionais, por exemplo. É sobre isso que se discorre na sequência.

A relação entre as três fases do ciclo do bem-estar humano é uma velha conhecida dos especialistas em direitos humanos e fundamentais. Ela surge nas discussões sobre mínimo existencial, proibição de retrocesso social, reserva do possível e obrigações (ou deveres) dos indivíduos consigo próprios, entre si, para o Estado e deste para aqueles, entre outros temas relacionados. E pode ser formulada da seguinte forma: os deveres são condição para a concretização de direitos, ou, em uma fórmula mais longa, a 
comprometimento social com a criação de oportunidades é condição para o retorno em bem-estar, de modo que o comprometer-se deve partir tanto dos indivíduos quanto do Estado e Organizações Internacionais - a estes dois últimos e outros órgãos que as eles se assemelham, doravante e para facilitar, são referidos, no texto, como PJPODI, isto é, pessoas jurídicas públicas e organismos de direito internacional.

Assumindo-se que as PJPODI atuam prestadoras de serviços públicos sem finalidades lucrativas e que necessitam de recursos, tanto para a sua manutenção quanto para realizar tais serviços, fica clara qual a obrigação que os indivíduos têm com elas: contribuir, na medida de suas capacidades. Quando o assunto é realização ou concretização de direitos a primeira ideia sobre contribuição conforme a capacidade é econômica ou financeira. No entanto, há outras possibilidades, como o trabalho voluntário. As possibilidades variam, mas o conteúdo central permanece o mesmo: os próprios indivíduos devem, ao analisar as suas manifestações de riquezas, habilidades e disponibilidades, inclusive de tempo, comprometer-se com a sociedade de alguma forma, as PJPODI entram em cena apenas para coordenar essas contribuições, quando existentes, ou criar mecanismos, às vezes até compulsórios (como o pagamento de tributos), para que elas aconteçam, se inexistentes ou insuficientes. Portanto, para a criação de oportunidades (segunda fase do ciclo), tem-se que o comprometimento social é imprescindível, porque ele que permitirá às PJPODI prestarem, mais adequadamente, os seus serviços de utilidade pública.

Obviamente que todo comprometimento social, seja do tipo que for, tem ao menos duas consequências: a primeira é que os indivíduo deixará de contar com os recursos que ele transferiu à sociedade; a segunda é que cada contribuição individual, considerada em conjunto com todas as demais, permitirá a formação de recursos necessários à prestação daqueles serviços (recursos humanos e recursos econômico-financeiros). Por isso é que a pedra de toque é a extensão e a profundidade da capacidade contributiva de cada pessoa. Por isso, embora um dever limite, por um lado, o exercício de direitos (efeito imediato), por outro cria oportunidades, as quais, se desfrutadas, retornam direitos (efeito mediato) (cf. GOMES CANOTILHO, 2003; SIQUEIRA, 2012). Essas oportunidades são denominadas, pelos especialistas, como direitos a uma prestação, ou seja, não é suficiente que estejam previstos em documentos formais, como constituições e tratados 
internacionais, para que se concretizem é necessário que alguém se comprometa a prestálos, realizá-los, dar-lhes eficácia.

O primeiro obstáculo que se coloca, então, no discurso sobre o custo das oportunidades é também o do significado da eficácia dos direitos a uma prestação. Afirmar que todos os direitos têm aplicação imediata, não é o mesmo que dizer que todos os direitos têm eficácia, como aponta Sarlet (2009). Pode-se dizer, na esteira dos ensinamentos de Silva (2000), que aplicabilidade é a aptidão de produzir efeitos, ou seja, de ter eficácia, como prefere Sarlet (2009), enquanto esta diz respeito aos efeitos produzidos em si. Por isso, ao dizer que "os direitos têm aplicação imediata", o sentido adotado não é de que eles produzem efeitos imediatos, e sim que eles têm a capacidade imediata de produzir. Eis a diferença: dizer que um determinado direito é eficaz significa afirmar que ele já foi aplicado e produz efeitos. Logo, nem todos os direitos têm igual aplicabilidade, uma vez que as normas das quais eles são extraídos podem ter mais ou menos facilidade para produzir efeitos. É isso o que auxilia na diferenciação entre liberdades (bem-estar) e prestações (oportunidades): enquanto o bem-estar prescinde de qualquer tipo de intervenção, desde que os indivíduos possuam meios para usufruí-lo, razão pela qual é também referido como autonomia, as oportunidades necessitam ser criadas, prestadas, para que possam ter a chance de, acaso exercidas, gerar como retorno o bem-estar.

O segundo obstáculo é eleger, entre todas as oportunidades possíveis de criar, aquelas imprescindíveis, a fim de que os recursos existentes sejam adequadamente alocados, para, então, minimizar os custos, o que tem aptidão para redundar em uma ótima relação de custo-benefício. A essa questão pode-se denominar de o problema do mínimo existencial. O conceito teórico, diante da clareza da expressão, prescinde esclarecimentos, o que não ocorre com a delimitação do bloco de oportunidades mínimas devidas a todo e qualquer ser humano, para o seu adequado desenvolvimento e para uma vida minimamente digna. As oportunidades que compõem esse bloco são, indubitavelmente, necessidades (para uma distinção entre necessidades e preferências, cf. De LUCAS e AÑóN ROIG, 1990; De VITA, 2007; WALZER, 2003; AÑóN ROIG, 1994; NINO, 1990), que podem, por isso, ser exigidas em face de quem tenha a obrigação de prestálas. Todavia, o problema da eleição a respeito de quais oportunidades seriam necessárias permanece, já que não se pode, em razão de critérios de espaço e de tempo, estabelecer 
uma lista fixa e imutável, como critica Sen (2005), que é inapropriada para a eficácia dos direitos. Nesse passo, a metodologia mais adequada parece ser o estabelecimento de uma espécie de padrão de vida ("standard of living") com uma lista-padrão de oportunidades, variáveis conforme contexto, gênero e outras peculiaridades. A ONU, por exemplo, dentro de um contexto internacional dos direitos, inclusive em termos humanitários, criou, a partir de estudos, uma lista com 17 metas para o desenvolvimento sustentável, as quais se direcionam ao fim da pobreza, à proteção do planeta e à garantia de prosperidade para todos e que podem, assim, ser vistas como uma lista-padrão para o mínimo existencial, a partir da qual se pode extrair quais as oportunidades a serem realizadas. Trata-se, à evidência, de uma perspectiva baseada nos deveres humanitários como condição para gerar prosperidade ou bem-estar a todas as pessoas, inclusive àquelas em situação de clara desvantagem em situação de conflitos, como as PcD e os idosos.

A partir da resolução desses dois problemas é possível destacar que as oportunidades não surgem imediatamente com a assunção do comprometimento social, é necessário que haja sempre no mínimo uma pessoa empenhada em concretizá-las, tornálas eficazes. Se, por um lado, as pessoas jurídicas públicas (Estados) e as organizações internacionais têm a obrigação estatutária de obter recursos para que uma determinada lista-padrão se torne minimamente real; por outro lado, cada indivíduo tem o dever, enquanto ser humano, de se comprometer, segundo a sua capacidade, a ajudar o seu semelhante. Do contrário, a tendência, cada vez mais proeminente, é a degradação da humanidade, com a aceleração da diminuição do bem-estar humano.

\section{CONSIDERAÇÕES FINAIS}

A proposta do artigo, como se pode depreender das análises feitas, é simples: para que haja o aumento da concretização de direitos humanos e, assim, do bem-estar humano em geral, basta o comprometimento social, que se traduz, também, em cumprir deveres, a fim de que sejam geradas oportunidades para aqueles que delas mais necessitam.

A partir disso é possível extrair algumas conclusões, a partir dos desenvolvimentos feitos, sobre a proteção eficaz dos direitos das pessoas com deficiência submetidas, direta ou indiretamente, a uma situação de conflito: 
1. O direito internacional humanitário é o conjunto de regras que procuram, por questões humanitárias, limitar os efeitos dos conflitos armados e promover a proteção concreta das pessoas que de alguma forma tenham sido submetidas a eles;

2. Apesar da divergência nos conceitos de deficiência (perspectiva contemporânea e tradicional) existe um ponto de convergência que está em entender a deficiência como um elemento inevitável da experiência humana, um aspecto fundamental da diversidade humana;

3. Há no universo normativo do direito internacional público um rol significativo de direitos das pessoas com deficiência, e o reconhecimento de determinados direitos, embora seja aclamável, nada mais significa, portanto, que tinta no papel, uma vez que os direitos positivados são genéricos e sua normatização não observa a individualidade, padecendo, portanto, de efetividade;

4. É necessário tomar medidas efetivas para garantir o comprometimento social voltado para a criação de oportunidades adequadas para que as pessoas com deficiência possam exercer os seus direitos, da maneira que as coloquem em uma situação equitativa com todas as demais (excluindo, assim, a sua situação de vulnerabilidade), para exercerem o seu livre-arbítrio (liberdades);

5. Há documentos internacionais voltados para a busca de igualdade de oportunidades para as pessoas com deficiências, dos quais se podem citar: a Resolução da ONU 37/52, de 1982 - Programa de Ação Mundial para as Pessoas Deficientes; a Resolução da ONU 48/96, de 1993 - Normas sobre Equiparação de Oportunidades para Pessoas com Deficiência. Todavia, nenhum deles documentos direciona-se especificamente à proteção humanitária, portanto, devem ser complementares em relação às quatro Convenções de Genebra de 1949 e seus Protocolos Adicionais de 1977, que compõem o núcleo do direito internacional humanitário, tendo como propósito proteger pessoas que não participam das hostilidades;

6. A proteção e a segurança, ambas em nível jurídico, das pessoas com deficiência submetidas a conflitos armados são feitas por um conjunto, não codificado nem consolidado, de documentos voltados para a atuação dos Estados no oferecimento de oportunidades que sejam adequadas ao exercício de direitos reconhecidos à comunidade em geral. 
A partir dessas considerações, o trabalho lança as bases de uma teoria voltada para dar eficácia aos direitos humanos a partir do necessário e prévio cumprimento de deveres: a teoria do ciclo do bem-estar humano. A teoria é dividida em três fases interdependentes, sendo a primeira delas o comprometimento social, que consiste não apenas em mudanças jurídicas, mas, também, em uma mudança cultural da própria sociedade, imputando a cada pessoa, conforme a sua capacidade de contribuir - não só com dinheiro, mas também com esforço e outras formas - com a sociedade, o dever de assumir o compromisso de realizar a equidade, em razão do objetivo fundamental da humanidade, a cooperação entre os povos. Apesar de a teoria se desenvolver em três partes (comprometimento social, oportunidades e bem-estar), apenas a primeira tem forte e presente relação com o ponto de vista dos deveres.

Em geral e por fim, pode-se afirmar que as fases dialogam e concorrem para o sucesso da teoria do bem-estar humano, uma vez que as oportunidades não surgem imediatamente com a assunção do comprometimento social, é necessário que haja sempre no mínimo uma pessoa empenhada em concretizá-las, torná-las eficazes, por meio da criação de oportunidades.

\section{REFERENCIAS}

ALMEIDA, Fábio Portela Lopes de. As origens evolutivas da cooperação humana e suas implicações para a teoria do direito. Revista direito GV, vol. 9, n. 1, jan./jun. 2013.

ALT, Vivian. Como crises humanitárias aumentam a vulnerabilidade de pessoas com deficiência. Politike, 14/12/2017. Disponível em:

<http://politike.cartacapital.com.br/como-crises-humanitarias-aumentamvulnerabilidade-de-pessoas-com-deficiencia/>. Acesso em: 1 abr. 2019.

Alt, Vivian. Como incluir pessoas com deficiência em respostas humanitárias. Politike, 31/01/2018. Disponível em: <http://politike.cartacapital.com.br/como-incluir-pessoascom-deficiencia-em-respostas-humanitarias-2/>. Acesso em: 1 abr. 2019.

Amiralian, Maria LT; PINTO, Elizabeth B.; GHIRARDI, Maria IG; LiChTIG, Ida; MaSini, Elcie FS; PASQUALIn, Luiz. Conceituando deficiência. Revista de Saúde Pública, vol. 34, n. 1, 2000.

AÑón RoIG, Maria José. Necesidades y derechos: un ensayo de fundamentación. Madrid: Centro de Estudios Constitucionales, 1994. 
BAMPI, Luciana Neves da Silva; GuILHEM, Dirce; Alves, Elioenal Dornelles. Modelo social: uma nova abordagem para o tema deficiência. Revista Latino-Americana de Enfermagem, vol. 18, n. 4, jul./ago. 2010.

BARCEllos, Ana Paula de; CAMPANTe, Renata Ramos. A acessibilidade como instrumento de promoção de direitos fundamentais. In: In: FERRAZ, Carolina Valença;

LEITE, George Salomão; LEITE, Glauber Salomão; LEITE, Glauco Salomão (coord.). Manual dos direitos da pessoa com deficiência. São Paulo: Saraiva, 2012.

BAUMAn, Zygmunt. Amor líquido: sobre a fragilidade dos laços humanos. Trad. Carlos Alberto Medeiros. Rio de Janeiro: Zahar Editor, 2004.

BAYERTZ, Kurt. Four uses of "solidarity". In: BAYERTZ, Kurt (ed.). Solidarity. Dordrecht: Kluwer Academic Publishers, 1999.

BEZERRA, Matheus Ferreira. Acessibilidade ao trabalho: a inserção do deficiente no mercado de trabalho. Revista de Direito do Trabalho, vol. 34, n. 130. São Paulo: Revista dos Tribunais, abr./jun., 2008.

BobBio, Norberto. A era dos direitos. Trad. Carlos Nelson Coutinho. Rio de Janeiro: Ed. Campus, 1992.

BOYD, Robert; RICHERSON, Peter J. Culture and the evolution of human cooperation. Philosophical Transactions of The Royal Society B, vol. 364, 2009.

BOYD, Robert; RICHERSON, Peter J. Why culture is common, but cultural evolution is rare. Proceedings of the British Academy, vol. 88, 1996.

CANDIDO, Maria Regina. Magia do katádesmos: téchne do saber fazer. Hélade - Revista Eletrônica de História Antiga, vol. 2, 2001.

Comitê InTERnacional da CRuZ Vermelha. As Convenções de Genebra de 1949 e seus Protocolos Adicionais. Disponível em: <https://www.icrc.org/pt/doc/war-andlaw/treaties-customary-law/geneva-conventions/overview-geneva-conventions.htm > e <http://www.mpsp.mp.br/portal/page/portal/cao_civel/normativa_internacional/Sistema _ONU/DH.pdf $>$. Acesso em: 20 maio 2019.

CORE HumANITARIAN STANDARD. Norma Humanitária Essencial para a Qualidade e Prestação de Contas, 2014. Disponível em: <https://corehumanitarianstandard.org/thestandard/language-versions>. Acesso em: 1 abr. 2019.

COUSER, Thomas. Disability as diversity: a difference with a difference. Ilha do Deserto, n. 48, jan./jun. 2005.

CufF, Benjamin MP; Brown, Sarah J; TAYLOR, Laura; HowAT, Douglas J. Empathy: a review of the concept. Emotion Review, vol. 8, n. 2, 2016. 
De LuCAS, Javier; AÑón RoIG, Maria José. Necesidades, razones, derechos, Doxa, n. 7, 1990.

DE ViTA, Álvaro. A justiça igualitária e seus críticos. 2. ed. São Paulo: Martins Fontes, 2007.

DHANDA, Amita. Construindo um novo léxico dos direitos humanos: Convenção sobre os direitos das pessoas com deficiências. SUR - Revista Internacional de Direitos Humanos, vol. 5, n. 8, jun., 2008.

DINIZ, Debora. O que é deficiência. São Paulo: Brasiliense, 2010.

Diniz, Debora; BARBosa, Lívia; SANTOS, Wederson Rufino dos. Deficiência, direitos humanos e justiça. SUR - Revista Internacional de Direitos Humanos, vol. 6, n. 11, dez. 2009.

DinIZ, Debora; MEDEIROS, Marcelo. Reflexões sobre a versão em português da Classificação Internacional de Funcionalidade, Incapacidade e Saúde. Cadernos de Saúde Pública, vol. 23, n. 10, out. 2007.

DUSSEL, Enrique. De la fraternidad a la solidaridad (hacia una política de la liberación). Pasos (segunda época), n. 126, jul./ago. 2006.

FARIAS, Norma; BuCHALlA, Cassia Maria. A Classificação Internacional de Funcionalidade, Incapacidade e Saúde da Organização Mundial da Saúde: conceitos, usos e perspectivas. Revista Brasileira de Epidemiologia, vol. 8, n. 2, 2005.

FoRSYTHE, David P. Humanitarian protection: the International Committee of the Red Cross and the United Nations High Commissioner for Refugees. International Review of the Red Cross, vol. 83, n. 843, set. 2001.

Gomes Canotilho, José Joaquim. Direito constitucional e teoria da constituição, 7. ed., Coimbra: Almedina, 2003.

HANDICAP INTERNATIONAL. Disability in humanitarian context: views from affected people and field organisations, 2015. Disponível em: <https://handicapinternational.ch/sites/ch/files/documents/files/disability-humanitarian-context.pdf>. Acesso em: 1 abr. 2019.

HANDICAP INTERNATIONAL. Vulnerability assessment framework. Disponível em: $<$ https://humanity-inclusion.org.uk/sites/uk/files/documents/files/2016-11-disabilityuniversal-indicator-jordan-unhcr.pdf > . Acesso em: 18 maio 2019.

HENRICH, Joseph; HENRICH, Natalie. Culture, evolution and the puzzle of human cooperation. Cognitive Systems Research, vol. 7, 2006.

Hespanha, António Manuel; Beleza, Teresa Pizarro. On witches, fairies and unicorns. Perplexities about an apparently neat idea: are human rights a dire illusion? In: FABRIZ, Daury Cesar; Peter Filho, Jovacy; SIQUeIRA, Julio Pinheiro Faro Homem de; UlHOA, 
Paulo Roberto; Fuchs, Horst Vilmar (coord.). O tempo e os direitos humanos. Rio de Janeiro: Lumen Juris, 2011.

Hutchison, Tom. The classification of disability. Archives of Disease in Childhood: The Journal of the British Paediatric Association, n. 73, 1995.

INTERNATIONAL COMMITTEE OF THE RED CROSS. What is international humanitarian law? Disponível em: <https://www.icrc.org/en/doc/assets/files/other/what_is_ihl.pdf>. Acesso em: 25 mar. 2019.

IOANNIDOU, I.; KONSTANLIKAKI, V. Empathy and emotional intelligence: what is it really about? International Journal of Caring Sciences, vol. 1, n. 3, 2008.

KerR, Benjamin; Godfrey-SMith, Peter; Feldman, Marcus W. What is altruism? Trends in Ecology and Evolution, vol. 19, n. 3, 2004.

KHALIL, Elias L. What is altruism? Critical commentary. Journal of Economic Psychology, vol. 25, 2004.

LyRA, José Francisco Dias da Costa; PreIs, Marco Antônio; SiQueIRA, Julio Pinheiro Faro Homem de; FABRIz, Daury César. A era dos deveres: a necessidade de um estatuto completo da pessoa humana para a eficácia social dos direitos. Cuestiones Constitucionales - Revista Mexicana de Derecho Constitucional, 2020 (no prelo).

MACFARQUHAR, Larissa. A vida pelos outros: escolhas altruístas no limite da ética. Trad. Liliana Negrello e Christian Schwartz. São Paulo: Editora Companhia das Letras, 2018.

MARTEL, Letícia de Campos Velho. Adaptação razoável: o novo conceito sob as lentes de uma gramática constitucional inclusiva. SUR - Revista Internacional de Direitos Humanos, vol. 8, n. 14, 2011.

Melis, Alicia P.; Semmann, Dirk. How is human cooperation different? Philosophical Transactions of the Royal Society B, vol. 365, 2010.

MITRA, Sophie. The capability approach and disability. Journal of Disability Policy Studies, vol. 16, n. 4, 2006.

Nino, Carlos Santiago. Autonomía y necesidades básicas, Doxa, n. 7, p. 24, 1990 ORGANIZAÇÃO DAS NAÇÕES UNIDAS. Normas sobre Equiparação de Oportunidades Resolução 48/96. Disponível em: <http://www.ampid.org.br/ampid/Docs_PD/Convencoes_ONU_PD.php\#normas1>. Acesso em 20 maio 2019.

ORGaniZAÇÃo das NAÇões UnidAS. Programa de Ação Mundial para as Pessoas Deficientes - Resolução 37/52, de 1982. Disponível em:

$<$ https://www2.camara.leg.br/atividade-legislativa/comissoes/comissoes- 
permanentes/cdhm/comite-brasileiro-de-direitos-humanos-e-politicaexterna/ProgAcMundPessDef.html>. Acesso em: 20 maio 2019.

PIOVESAN, Flávia. Convenção da ONU sobre os direitos das pessoas com deficiência: inovações, alcance e impacto. In: FERRAZ, Carolina Valença; LEITE, George Salomão;

LEITE, Glauber Salomão; LeITE, Glauco Salomão (coord.). Manual dos direitos da pessoa com deficiência. São Paulo: Saraiva, 2012.

RAND, David G.; NowAK, Martin A. Human cooperation. Trends in Cognitive Sciences, vol. 17, n. 8, ago. 2013.

RAWLS, John. A theory of justice. Cambridge: Belknap Press, 1999.

RICHERSON, Peter J.; BOYD, Robert. Hot by genes alone: how culture transformed human evolution. Chicago: The University of Chicago Press, 2005.

Saramago, José. Discurso de Estocolmo de 10 de dezembro de 1998: uma proposta para a Declaração Universal dos Deveres Humanos. Lisboa: Fundação José Saramago, 1998. Disponível em: <https://pt.scribd.com/doc/269455895/Jose-Saramago-DiscursoPremio-Nobel>. Acesso em 11 fev. 2018.

SARLET, Ingo Wolfgang. A eficácia dos direitos fundamentais: uma teoria geral dos direitos fundamentais na perspectiva constitucional. 10. ed. Porto Alegre: Livraria do Advogado, 2009.

SEn, Amartya K. Desenvolvimento como liberdade. Trad. Laura Teixeira Motta. São Paulo: Editora Companhia das Letras, 2007.

SEN, Amartya K. Human rights and capabilities. Journal of Human Development, vol. 6, n. 2. Kentucky: Routledge, 2005.

SEN, Amartya K. Sobre ética e economia. Trad. Laura Teixeira Motta. São Paulo: Editora Companhia das Letras, 2008.

Silva, José Afonso da. Aplicabilidade das normas constitucionais. 4. ed. São Paulo: Malheiros, 2000.

SiQUeIRA, Julio Pinheiro Faro Homem de. A procura do bem-estar e a abordagem seniana das capacidades na concretização dos direitos fundamentais. In: MACHADO, Felipe Daniel Amorim; BARROS, Flaviane de Magalhães (org.). Hermenêutica e Jurisdição Constitucional: anais do $5^{\circ}$ Congresso de Constituição e Processo. Belo Horizonte: Instituto de Hermenêutica Jurídica/Initia Via Editora, 2013.

SiQUEIRA, Julio Pinheiro Faro Homem de. Deveres como condição para a concretização de direitos. Revista de Direito Constitucional e Internacional, vol. 79. São Paulo: Ed. RT, abr./jun. 2012. 
SiqueIRA, Julio Pinheiro Faro Homem de; MTEwa, Andrew G. The loftiest towers rise from the ground: how UNDP and the SDGs contribute for a more peaceful world (mimeo).

StUEBER, Karsten. Empathy. In: ZALTA, Edward N. (ed.). The Stanford Encyclopedia of Philosophy, 2018. Disponível em: <https://plato.stanford.edu/entries/empathy/>. Acesso em 29 mar. 2019.

TITCHENER, Edward Bradford. A text-book of psychology. New York: The Macmillan Company, 1928.

TITCHENER, Edward Bradford. Introspection and empathy. Dialogues in Philosophy, Mental and Neuro Sciences, vol. 7, n. 1, 2014.

TRIVERS, Robert L. The evolution of reciprocal altruism. The Quarterly Review of Biology, vol. 46, n. 1, mar. 1971.

UnITED NATIONS. Sendai Framework for Disaster Risk Reduction 2015-2030.

Disponível em: <https://www.unisdr.org/we/inform/publications/43291>. Acesso em: 1 abr. 2019.

United NATIONS StATISTICAL COMMISSION. Washington Group on disability statistics. Disponível em: <http://www.washingtongroup-disability.com/>. Acesso em: 18 maio 2019.

VAlladARes, Gabriel Pablo. El Comité Internacional de la Cruz Roja (CICR) y su contribución a los últimos desarrollos del derecho internacional humanitario. Anuário Brasileiro de Direito Internacional, vol. 1, 2006.

WAAL, Frans de. A era da empatia: lições da natureza para uma sociedade mais gentil. Trad. Rejane Rubino. São Paulo: Ed. Companhia das Letras, 2010.

WALZER, Michael. Esferas da justiça: uma defesa do pluralismo e da igualdade. Trad. Jussara Simões. São Paulo: Martins Fontes, 2003.

World Health ORganization. Disability and health (16 January 2018). Disponível em: <https://www.who.int/en/news-room/fact-sheets/detail/disability-and-health>. Acesso em: 1 abr. 2019.

WORLD HEALTH ORGANIZATION. International classification of impairments, disabilities, and handicaps: a manual of classification relating to the consequences of disease. Geneva: WHO, 1980.

World HuMANITARIAN SUMMIT. Charter on Inclusion of Persons with Disabilities in Humanitarian Action, 2016. Disponível em: <http://humanitariandisabilitycharter.org/> . Acesso em: 1 abr. 2019.

ZIMMERLING, Ruth. Necesidades básicas y relativismo moral, Doxa, n. 7, p. 24, 1990. 
Quaestio Iuris

Trabalho recebido em 03 de julho de 2019

Aceito em 01 de junho de 2020 